\title{
Chapter 13 \\ Predicting Biosecurity Threats: \\ Deployment and Detection of Biological Weapons
}

\author{
Kaitlin M. Volk and Trajan J. Gering
}

Understanding what kinds of biological weapons can be made with what sort of technology and by whom is an important component of biosecurity. An equally important component is understanding the different potential targets a biological weapon could be designed to attack, how the weapon would be deployed against these targets, and the available strategies to detect the creation and deployment of an illegal biological weapon. Understanding how a weapon could be deployed against specific targets affords decision makers a better picture of the current state and capabilities of biowarfare and bioterrorism that need to be protected against. Understanding current detection capabilities allows for a more informed discussion on biosecurity tools, and, more importantly, allows for the identification of critical gaps and research needs to improve risk-screening, detection, environmental remediation, and various other normatively beneficial and legitimate uses of emerging biotechnologies (Trump et al. 2020a). These two topic areas are discussed in this chapter.

\subsection{Methods of Deployment}

The Center for Disease Control and Prevention (CDC) classifies disease transmission into two primary categories: direct transmission and indirect transmission (CDC 2011). Concerning direct transmission, individuals pick up the disease through direct contact with an infected person or from direct contact with an environmental reservoir. This also includes droplet spread, in which the close-range spray of a sneeze or cough transmits a pathogen without the assistance of an intermediate object. Examples of natural outbreaks spread primarily through droplets

K. M. Volk $(\bowtie) \cdot$ T. J. Gering

ERDC-EL, US Army Corps of Engineers, Vicksburg, MS, USA

(C) The Author(s) 2021

B. D. Trump et al. (eds.), Emerging Threats of Synthetic Biology and Biotechnology, NATO Science for Peace and Security Series C:

Environmental Security, https://doi.org/10.1007/978-94-024-2086-9_13 
include the COVID-19 virus and the plague (Carniel 2002; Linkov et al. 2021). Additionally, researchers in 2012 modified a strain of avian influenza to be transmissible between mammals via respiratory droplets (Evans and Selgelid 2015). While direct transmission with droplets would restrict spread to only close-range encounters, it has proven to be a highly effective mode of transmission particularly in densely populated areas like cities.

In indirect transmission, a pathogen from a sick individual is left on/in an intermediate object and is transmitted to a healthy individual when they come into contact with the infected object. The CDC delineates three categories of indirect transmission: vehicle, vector, and airborne. In vehicle-based transmission, inanimate objects like food, water, biological products (e.g. blood), and fomites (e.g., clothing and utensils) are contaminated with the pathogen. A number of bioterrorism acts that utilized vehicle transmission exist. Letters were used in the 2001 anthrax attack that targeted media outlets and politicians. The Rajneeshee cult poisoned salad bars with Salmonella in order to influence a local election, using food as the vector for their biological attack. Researchers modeling a bioterror attack determined that terrorists could affect several hundred thousand individuals if they could cultivate and deploy enough biotoxin into a single milk-processing facility (Wein and Liu 2005). This is because the dairy processing industry is so heavily centralized. Many realms of the agriculture and food production industry are similarly centralized, increasing the risk of the transmission of pathogens to consumers through the ingestion of contaminated food or drink (Sobel et al. 2002). Contaminated blood, medicine, and other inanimate objects could also be used as vehicles (Shinwari et al. 2014), and the vehicle method could be particularly effective at attacking sequencing machines, as discussed further below (Faezi et al. 2019).

In vector-based transmission, organisms carry a pathogen and transmit it upon contact with humans (CDC 2011). Animal vectors are a common mode of transmission of natural outbreaks (e.g. mosquitos transmitting malaria and rats transporting the plague) (CDC 2011; Carniel 2002) and have been used in previous biological attacks (e.g., plague-ridden fleas released into China by Japan) (Franconi et al. 2018; Zilinskas 2017). Additionally, the majority of the novel human infectious agents that have emerged over recent decades have been zoonotic, meaning they were transmitted from animals to humans following a mutation (Franconi et al. 2018). Despite their proven effectiveness, little attention has been paid to animals as a means to start a biological attack, potentially due to the difficulty of obtaining, keeping, and releasing large amounts of any organism discreetly.

While much of the published biosecurity literature does not address specific modes of pathogen transmission, the airborne mode has received the most attention for its potential use in a biological attack (Yeh et al. 2013, NRC 1997, Anand 2018). In airborne-based transmission, pathogens are attached to dust or droplet nuclei suspended in the air. Concerns over the aerosolization of pathogens have existed for decades. The US Army Chemical Corps ran a series of experiments in the 1950s and 1960s to understand patterns of aerosol dispersal of biological weapons over short distances in cities, medium distances in rural communities, and extremely long distances across entire continents (NRC 1997). Using planes, the Chemical Corps 
dispersed zinc cadmium sulfide, Serratia marcescens, and Bacillus globigii over 33 urban and rural sites and large swaths of land from ocean to ocean and border to border. These latter experiments are known as Operation LAC, standing for "Large Area Coverage," and demonstrated that airborne biological weapons could cover extremely large geographical areas (NRC 1997). Japan, Iran, and Iraq at different times created bombs or missiles designed to aerosolize pathogens upon explosion (Zilinskas 2017). Similar concerns exist today with malicious terrorist or cult groups (Zilinskas 2017; Shinwari et al. 2014), in addition to concerns over the possibility of these groups using drones to remotely disperse pathogens (Anand 2018) or concealed aerosol containers to release an airborne pathogen in crowded and confined areas (Yeh et al. 2013).

Overall, while a synthetic pathogen could be spread in a variety of ways, the airborne mode of transmission would likely be the most effective mode for a largescale biological attack as it could be easily released by land or air, spread over a large area in a relatively short amount of time, and easily enter people's bodies through respiration.

\subsection{Targets}

Four main categories that biological weapons could be engineered to attack were identified in the literature. These targets include humans, agriculture, technology, and the environment. The ease with which these attacks could be carried out, consequences of the attack, and potential strategies to prevent the attack are presented below for each target.

\subsubsection{Humans}

Unsurprisingly, much of the focus on biological weapon production and defense have used humans as the target. A biological attack against humans could result in direct human deaths or illness, widespread fear and panic, economic loss, and costs related to the response and remediation of the pathogen (Elbers and Knutsson 2013). Human pathogens can be readily obtained from the environment or natural outbreak events and are found in laboratories of various security levels around the world (Gronvall 2015). Most of the work being done on synthesizing viruses from DNA ordered through DNA synthesizing organizations is done on human pathogens (De Vries 2017, Noyce et al. 2018, Berger 2019). With a few exceptions, including the U.S.'s use of biological weapons against plants in Vietnam, the majority of statesponsored synthetic biological weapon programs have focused on zoonotic human pathogens, especially Bacillus anthracis and Yersinia pestis (Kelle et al. 2010; Zilinskas 2017). 
The probability of an attack in the near future with biological weapons from state-actors, sub-state actors, and non-state actors seems to be admittedly low based on the low number of previous biological attacks, but the outcome of such an attack would be catastrophic and warrants preventative measures. Biological attacks will also become more likely as the cost and effort associated with synthetic biology and the creation of pathogens decreases. As demonstrated by natural outbreak events, pathogens have an innate ability to persist in a given location indefinitely, essentially remaining dormant in human or environmental reservoirs between outbreaks. Thus, an initial biological weapons attack could have long-term and cascading effects unseen in attacks with more-traditional weapons (Plianbangchang 2005).

Many laboratories that handle human pathogens have protective measures commensurate in level to the danger of the pathogens they are handling. Biosecurity levels range from 1, requiring the least amount of protective measures, to 4 , requiring the most. These regulations are put in place to reduce the risk of a pathogen being accidently released or of unauthorized personnel gaining access to the pathogen. However, not all laboratories around the world handling dangerous pathogens properly follow biosafety regulations, or take measures to reduce biosafety challenges via a 'safety-by-design' approach (Trump et al. 2020c). Outreach and support, both monetarily and intellectually, may be needed between countries to ensure all biological laboratories are properly protected. Biological journals also need to take responsibility for screening papers so that information that could be easily used by nefarious actors to create biological weapons doesn't become readily available. This debate over the risk of publishing dual-use research and the role of academic journals is evident in the ongoing scrutiny of a publication detailing the synthesis of horsepox, a close relative to the smallpox virus (Noyce and Evans 2018; Yong 2018), and is yet to be resolved.

\subsubsection{Agriculture}

Biological attacks against agriculture and livestock, also known as agroterrorism, would result in large negative consequences despite receiving less attention in the literature. Agroterrorism is defined as the introduction of an animal or plant infectious disease to induce fear in people, threaten social stability, and cripple a nation's economy (Yeh et al. 2013). Animal and plant infectious diseases include both viruses, such as foot in mouth disease (FMD), rinderpest, and avian influenza; and bacteria, such as anthrax, brucellosis, and glanders (Yeh et al. 2012). While synthetic viruses and bacteria are of the most serious concern currently, agroterrorism could be susceptible to larger multicellular organisms as advancements in synthetic biology are made on that front. Traditional agricultural pests or diseases, such as the Russian wheat aphid (Diuraphis noxia) or ring rot (Clavibacter machinanensis), could be modified to be more resistant to pesticides or environmental conditions, thereby increasing their potential damage (Anand 2018; Getz and Dellaire 2018). 
Agroterrorism lacks some of the cognitive and cultural shock of bioterrorism and has rarely been used in the past. One of the few examples of an offensive agroterrorism program is the Japanese Unit 100, which was dedicated to creating biological weapons for use against animals during WWII (Zilinskas 2017). Agroterrorism could be an easier and safer avenue of attack for the attacker (Elbers and Knutsson 2013; Anand 2018). Animal and plant infectious diseases are often abundant in the natural environment, making them relatively easy to obtain. Would-be attackers can handle the disease with little to no threat to their own lives or the lives of those people they care about. For example, while the use of a human pathogen during war has a very high risk of spreading back to the home nation, agricultural pathogens will be more contained and less likely to backfire especially if strains of a crop or livestock specific to the attacked location are targeted. Farms are often unsecured and geographically dispersed, making it easy for attackers to deploy a pathogen. Livestock and crops are kept in highly concentrated areas and livestock are frequently exposed to other herds or flocks during long-distance transport, effectively providing a built-in dispersal mechanism. Lastly, livestock often lack any resistance to pathogens that are prevalent in other countries, and veterinarians or agricultural officials are less likely to test for or recognize diseases that aren't endemic to their region (Elbers and Knutsson 2013).

Overall, agroterrorism with a synthetic pathogen is an easier route of attack for a terrorist organization than a traditional biological attack against humans. A biological attack against important crops or livestock could have devastating effects on the economy and social well-being of a country, as has been seen in natural agricultural outbreaks (e.g. the Irish potato famine in 1845 or the mass culling of pigs infected with African swine fever in Ukraine in 2012). The threat of a biological attack against agriculture could be reduced by preventing actors from acquiring agricultural pathogens, increasing security on farms, developing early detection systems (including the education of farmers and veterinarians on foreign agricultural pathogen identification) and stockpiling livestock vaccines (Yeh et al. 2013; Anand 2018). Restrictions on the use of agricultural pathogens in synthetic biology experiments could also be applied in a way similar to those on human pathogens.

\subsubsection{Technology}

Synthetic biology has also been shown to be effective at attacking technology (Berger 2019; Ney et al. 2017). DNA is a relatively stable platform capable of storing large amounts of information. Normally this information is biological, but scientists have begun to look at DNA as a way to store large data and datasets, including images, audio, and videos (Berger 2019). To demonstrate the capability of technology to store and recover data from DNA, researchers at Harvard University recently used CRISPR-based tools to encode a GIF of a galloping horse into the genomes of living bacteria (Escherichia coli) (Shipman et al. 2017). However, if one is able to store data and code in DNA, then one should also be able to store malicious code. 
In the same year that scientists at Harvard were storing GIFS in E. coli, scientists at the University of Washington were encoding malware into a segment of DNA to successfully gain remote control of the computer that sequenced the malicious DNA (Ney et al. 2017). Many next-generation DNA sequencing (NGS) systems use a 2-bit DNA encoding scheme to read and store genetic information - $\mathrm{A}$ is coded as $00, \mathrm{C}$ as $01, \mathrm{G}$ as 10 , and $\mathrm{T}$ as 11 . The authors of the study encoded a straightforward and commonly available computer bug and then transferred the computer code into the corresponding nucleotide sequence. They then bought this sequence from a gene synthesis company that creates synthetic gene fragments. Upon receiving the malicious synthesized DNA fragment and running the fragment through a sequencer and downstream analysis program, the authors gained full control of the computer attached to the sequencer.

It is important to note that the authors deliberately introduced a vulnerability into the analysis program they attacked prior to sequencing the malicious DNA. However, the authors of this study analyzed a number of NGS analysis programs and found that they are 11 times more likely to use insecure programming functions than nonNGS control programs ( $p=0.027$, Ney et al. 2017). They concluded that NGS programs do not follow best software security practices and need to be updated so as to be more robust against attacks. The authors were limited in the kind of malware they could encode into DNA because of current restrictions in the length of DNA fragments that can be sequenced and requirements for sequence stability. Advancements in NGS systems to sequence longer segments of DNA will increase the length and complexity of malware that can be encoded in DNA, and advancements in synthesizing DNA could overcome current structural requirements and also allow for a wider variety of malware. Advancements in DNA sequencing and synthesizing are ongoing as researchers innovate in pursuit of beneficial synthetic biology applications.

With the encoding of malware into DNA, any laboratory or company that sequences DNA becomes vulnerable to an attack on their computer system. Attackers could target the human biobanks of companies like 23andMe or AncestryDNA to expose the genetic information of earth's population. This could allow attackers to synthesize a pathogen that is fatal to a small subset of people with the targeted genetic sequence but is benign to the general population (Faezi et al. 2019). Attackers could also target high-level laboratories that work with pathogens to crash their computers or gain access to confidential files. Malicious DNA could be sent directly to these sequencing services (e.g., a spit sample sent to an ancestry database) or introduced by spraying malicious DNA on surfaces that are likely to be swabbed for DNA analysis (e.g. a countertop during a health inspection or criminal investigation) or come into contact with the sequencing machine (e.g. rubber gloves or lab coats) (Faezi et al. 2019).

As advancements in NGS systems are made, updates to bring NGS software in line with best security practices should be prioritized to reduce the risk posed by malicious DNA (Ney et al. 2017). Sequencing companies should also take more responsibility in identifying suspicious DNA sequences and denying or reporting the order. One group of researchers had already started to develop a technique to 
detect and exclude malicious DNA by checking the sequenced DNA against known sequences before it was fully processed (Islam et al. 2019). As this is a new emerging threat, more effort needs to be applied to increase security at every level, including synthesizing DNA, sequencing DNA, analyzing sequenced data, and securing valuable genetic databases.

\subsubsection{The Environment}

To date, no literature that discussed using synthetic biology to directly attack the natural environment has been found. There is ongoing research focused on using gene drives and horizontal gene transfer in the open environment for beneficial purposes, including modifying mosquitos so that they are resistant to malaria (Gantz et al. 2015) and modifying coral symbionts to be more resistant to coral bleaching (Cleves et al. 2018). There are inherent risks of releasing engineered organisms into the environment since the effects of such organisms on the local community are largely unknown. However, that debate has been ongoing for decades and is outside of the scope of biosecurity. Theoretically, it could become possible for malicious actors to utilize gene drives to purposefully collapse species critical to the functioning of an ecosystem without detection. However, the technique is complicated and still in its infancy. Gene drives would be particularly ineffective against long-living species with long generation times since it would take an exorbitantly long time to propagate the deleterious gene throughout the population through natural reproduction. Overall, biological attacks against the natural environment are a very indirect route of causing harm to an enemy. Humans and agriculture are much more likely targets since harm can be inflicted almost immediately and research in engineering these sorts of pathogens is more robust. Advancements in synthetic biology that enhance the capabilities of gene drives or other methods that could be deployed against the natural environment should still be tracked as this could become a target in the future.

\subsection{Screening Techniques}

Effective biosecurity should be able to identify when (a) a biological weapon is being produced in order to prevent its full production and deployment and (b) a biological weapon has been deployed in order to attribute the attack and to start remediation. Current screening methods and gaps are discussed below for both of these phases. 


\subsubsection{Pre-deployment: Gene Synthesis}

Production of a biological weapon with synthetic biology has the potential to be identified and prevented as soon as a nefarious actor tries to purchase DNA fragments from gene synthesis companies. Many U.S. companies conduct background checks on people placing orders and compare the ordered sequence against libraries of listed pathogens as advised by the U.S. National Institute of Health (NIH) (Gronvall 2015; Ahteensuu 2017). If an ordered sequence too closely matches that found within the genome of a listed pathogen then the order isn't fulfilled and authorities may be contacted. However, not all gene synthesis companies follow these steps, and the same recommendations are not in place in other countries (Gronvall 2015). The International Gene Synthesis Consortium (IGSC) is one entity trying to fix this issue by alerting all member companies if one company receives a suspicious order. This prevents malicious actors from simply ordering from another member company if they are denied. However, members of IGSC make up a minority of companies that synthesize DNA but do represent the majority of the market share (Frazar et al. 2017). As a growing number of smaller businesses performing gene synthesis open with increased ease and decreased cost of synthesis, security at this level could become more of a concern. Effort should be made to create similar legislature/recommendations as the NIH in other countries for gene synthesis companies, or to incorporate more of these companies into the IGSC.

Even with the IGSC and national recommendations, however, there is no formal or widely accepted method for prioritizing and listing pathogens (Salerno and Hickok 2007), and the current list of pathogens is not comprehensive (it does not include many agricultural diseases). The list will quickly become insufficient as synthetic biology progresses, and the process of screening gene sequences will become more complicated (Elbers and Knutsson 2013). For instance, scientists have created strains of yeast that can produce opiates and biological toxins (Cirigliano et al. 2017), but it would be illogical to categorize yeast as an agent of concern since it is usually benign and a key research organism. Additionally, malicious actors could hide and later extract desired sequences in a longer sequence or split the sequence among multiple companies to avoid detection (Frazar et al. 2017). Using a list of pathogens to screen for dangerous orders also does not address the encoding of computer malware into DNA as discussed above (Ney et al. 2017). Stronger international policies that require gene synthesis companies to run checks on people placing orders and the orders themselves could be enacted. The government could also monitor the sale and movement of the equipment needed to cut, combine, and propagate gene sequences. The U.S. Department of Commerce currently maintains a list of equipment of concern, but almost none of this equipment relates to synthetic biology (Frazar et al. 2017). 


\subsubsection{Post-deployment: Pathogen Detection}

Once a pathogen is created and deployed, there are ways to identify that an outbreak is occurring and what engineered pathogen is responsible (Trump et al. 2018). Pathogens are often identified using traditional molecular diagnostic methods during natural outbreaks. Some techniques are specific for humans, animals, or plants, but all can be used for an intentional outbreak. Examples include basic and advanced polymerase chain reaction (PCR) technology, fluorescence in situ hybridization (FISH), antibody-based immuno-assays, biochemical testing, mass spectrometry, and enzyme-linked immunosorbent assay (ELISA) (Anand 2018; Krishan et al. 2017). ELISA has been suggested as a viable and rapid way of testing for pathogens/biotoxins released into centralized food processing plants (Wein and Liu 2005). The majority of these techniques, however, must be processed in a laboratory and are constrained by the number of samples they can analyze. Some are also expensive, prone to false-positives, and insensitive to certain bacteria. Optical techniques, such as immunofluorescence (IF), flow cytometry (FCM), thermography, and gas chromatography are useful in detecting diseases in plants (Anand 2018). These too are limited by sensitivity to environmental conditions during measurements and some, like thermography, indicate that a disease is present but cannot diagnose specific diseases.

Synthetic biology can be used to create pathogens that circumvent standard methods of detection, meaning that existing diagnostic tools could return a false negative when analyzing a new synthetically-developed pathogen (Gronvall et al. 2015). For example, the primary way of identifying $Y$. pestis was through the detection of antibodies to the F1 protein found on the outer membrane of the of bacteria. Knowing this, Russia successfully created a strain of $Y$. pestis that lacked the F1 protein in the 1980s, thereby rendering traditional identification methods useless (Zilinskas 2017). This demonstrates that pathogens could be deliberately engineered to avoid available detection techniques, which would delay detection and intervention and subsequently increase the outbreak severity (Gronvall 2015; Plianbangchang 2005). Synthesized pathogens' ability to avoid detection strengthens the argument for ever-evolving detection techniques, in addition to stronger policies around the creation of such pathogens in the first place.

Advancements in the fields of biotechnology, nanotechnology, and information technology should improve detection techniques (Trump et al. 2020b). Nanophytopathology is an emerging technique for the early detection of plant diseases (Anand 2018). Software programs utilizing crowdsourced data and evaluations are also becoming popular for detecting and mapping diseases, and could be used to identify biological attacks against both agriculture and humans (Anand 2018; Berger 2019). The first biological surveillance platform for human outbreaks, ProMed Mail, was created in 1994. It works by sharing and monitoring media, official reports, online information, local observations, and more to identify symptoms or signals that a new or unusual disease outbreak or toxic exposure is occurring (Berger 2019). This program is still alive today and includes over 70,000 members 
in 185 countries that review reports and engage in discussions on infectious diseases. A number of similar text analysis platforms that compile and analyze databases to identify biological attacks or natural outbreaks have also been launched. These platforms are all affected by the people reviewing the data, the type and language of data sources, region of incidents, and types of cases collected. For instance, the text analysis platform HealthMap identified the 2014 Western African Ebola outbreak a week before WHO declared the outbreak, but a failure in human moderators to recognize the trend identified by the platform caused delay (Berger 2019). Syndromic surveillance can also be used to detect a disease outbreak. Syndromic surveillance uses market data (e.g. the number of eggs being produced, amount of over-the-counter medication being bought, spike in searches about abdominal pain being) to detect when trends differ from the baseline that could indicate a human or agricultural disease outbreak (Elbers and Knutsson 2013; Berger 2019). Overall, the groundwork for early detection systems exists but can be greatly improved upon in the future as advanced computing capabilities increase.

Real-time sensors embedded in the environment that passively monitor for pathogens would be the ideal way of quickly recognizing a biological weapon attack (Shinwari et al. 2014). Biosensors use a recognition element, usually biological in origin, to bind to some component of a pathogen of interest in order to recognize and report that the pathogen is present (Sapsford et al. 2008). These reactions occur in specialized and highly sensitive bioprobes within biosensors. Unlike traditional ways of detecting pathogens, which can take days to complete in a laboratory, bioprobes can recognize specific pathogens within minutes in the field (Kim et al. 2015). One sensor could contain multiple probes focused on specific pathogens and recognize a pathogen from its size, DNA sequence, specific chemical reactions, antibodies, antigens, phage response, or aptamer binding (Petro et al. 2003; Kim et al. 2015). Since pathogens can be modified to avoid specific modes of detection (e.g., the exclusion of certain plasmids or antigens) (Zilinskas 2017), multiple probes using different means of detecting a single pathogen could be included in a single biosensor to increase security (Sapsford et al. 2008). However, screening for specific agents has its limitations, as discussed previously, so biosensors that could recognize novel pathogens or DNA against the natural background would be ideal. Detectors will likely become more accurate and useful as pattern recognition software and nanotechnology advances, as both of these would help to screen out background environmental contaminants, minimize false positives, and decrease detection time (Petro et al. 2003, Kim et al. 2015).

\subsection{Conclusion}

A biological attack utilizing a synthetic pathogen could prove disruptive to various receptors - making it critical to consider how to prevent, avoid, or ameliorate such challenges before they arise (Malloy et al. 2016; Trump et al. 2020d). The threat of attacks using other methods of deployment against less traditional targets (e.g. 
technology or the environment) should not be ignored. Increasing synthetic biology capabilities will increase the risk of more complicated biological attacks against all discussed targets, but will also increase our ability to detect pathogens in the environment with biosensors. A large focus, however, should be on preventing the creation of a synthetic pathogen in the first place, which can be accomplished through increased monitoring and regulation of gene synthesis orders, synthetic biology equipment, and distribution of sensitive information.

\section{Literature Cited}

Ahteensuu M (2017) Synthetic biology, genome editing, and the risk of bioterrorism. Sci Eng Ethics 23:1541-1561

Anand M (2018) A systems approach to agricultural biosecurity. Health Secur 16(1):58-68

Berger KM (2019) Emerging and enabling technologies. In: Singh SK, Kuhn JH (eds) Defense against biological attacks. Springer, Cham, pp 253-281

Carniel E (2002) The plague. C R Biol 325(8):851-853

Center for Disease Control and Prevention (CDC) (2011) Section 10: Chain of infection in Principles of Epidemiology in Public Health Practice, 3rd edn. An Introduction to Applied Epidemiology and Biostatistics. Available at https://www.cdc.gov/csels/dsepd/ss1978/ SS1978.pdf

Cirigliano A, Cenciarelli O, Malizia A, Bellecci C, Gaudio P, Lioj M, Rinaldi T (2017) Biological dual-use research and synthetic biology of yeast. Sci Eng Ethics 23:365-374

Cleves PA, Strader ME, Bay LK, Pringle JR, Matz MV (2018) CRISPR/Cas9-mediated genome editing in a reef-building coral. PNAS 115(20):5235-5240

De Vries RP, Peng W, Grant OC, Thompson AJ, Zhu X et al (2017) Three mutations switch H7N9 influenza to human-type receptor specificity. PLoS Pathog 13(6):e1006390. https://doi. org/10.1371/journal.ppat.1006390

Elbers A, Knutsson R (2013) Agroterrorism targeting livestock: a review with a focus on early detection systems. Biosecur Bioterrorism 11:S25-S35

Evans NG, Selgelid MJ (2015) Biosecurity and open-source: the promise and peril of distributed synthetic biological technologies. Sci Eng Ethics 21:1065-1083

Faezi S, Chhetri RR, Malawade AV, Chaput JC, Grover W, Brisk P, Al Faruque MA (2019) Oligosnoop: a non-invasive side channel attack against DNA synthesis machines. Network and Distributed Systems Security (NDSS) Symposium

Franconi R, Illiano E, Paolini F, Massa S, Venuti A, Demurtas OC (2018) Rapid and low-cost tools derived from plants to face emerging/re-emerging infectious diseases and bioterrorism agents. In: Radosavljevic V et al (eds) Defence against bioterrorism. Springer, Dordrecht, pp 123-139

Frazar SL, Hund GE, Bonheyo GT, Diggans J, Bartholomew RA, Gehrig L, Greaves M (2017) Defining the synthetic biology supply chain. Health Secur 15(4):392-400

Gantz VM, Jasinskiene N, Tatarenkova O, Fazekas A, Macias VM, Bier E, James AA (2015) Highly efficient Cas9-mediated gene drive for population modification of the malaria vector mosquito Anopheles stephensi. PNAS 112(49):6736-6743

Getz LJ, Dellaire G (2018) Angels and devils: dilemmas in dual-use biotechnology. Trends Biotechnol 36(12):1202-1205

Gronvall GK (2015) Mitigating the risks of synthetic biology. Council on Foreign Relations, Center for Preventative Action

Gronvall GK, Ravi S, Inglesby T, Cicero A (2015) Singapore-Malaysia-Indonesia-US dialogue on biosecurity. Health Secur 13(6):399-405 
Islam MS, Ivanov S, Robson E, Dooley-Cullinane T, Coffey L, Coolin K, Balasubramaniam S (2019) Genetic similarity of biological samples to counter bio-hacking of DNA-sequencing functionality. Nature 9(8684). https://doi.org/10.1038/s41598-019-44995-6

Kelle A, Nixdorff K, Dando M (2010) Strengthening BWC prevention of state-sponsored bioweapons. Bull At Sci 66(1):18-23

Kim J, Gedi V, Lee S-C, Cho J-H, Moon J-Y, Yoon M-Y (2015) Advances in anthrax detection: overview of bioprobes and biosensors. Appl Biochem Biotechnol 176:957-977

Krishan K, Baljinder K, Sharma A (2017) India's preparedness against bioterrorism: biodefence strategies and policy measures. Curr Sci 113(9):1675-1682

Linkov I, Keenan J, Trump BD (2021) COVID-19: systemic risk and resilience. Springer Nature

Malloy T, Trump BD, Linkov I (2016) Risk-based and prevention-based governance for emerging materials. Environ Sci Technol

National Research Council (NRC), Subcommittee on Zinc Cadmium Sulfide (1997) Toxicologic assessment of the Army's zinc cadmium sulfide dispersion tests. The National Academics Press, Washington, DC

Ney P, Koscher K, Orhanick L, Ceze L, Kohno T (2017) Computer security, privacy, and DNA sequencing: compromising computer with synthesized DNA, privacy leaks, and more. USENIX Security Symposium

Noyce RS, Evans DH (2018) Synthetic horsepox viruses and the continuing debate about dual use research. PLoS Pathog 14(10):e1007025

Noyce RS, Lederman S, Evans DH (2018) Construction of an infectious horsepox virus vaccine from chemically synthesized DNA fragments. PLoS One 13(1):e0188453. https://doi. org/10.1371/journal.pone.0188453

Petro JB, Plasse TR, McNulty JA (2003) Biotechnology: impact on biological warfare and biodefense. Biosecur Bioterrorism 1(3):161-168

Plianbangchang S (2005) Strategies of preparedness against the threat of biological warfare and bioterrorism in South-East Asia. Asian Biotechnol Dev Rev 8(1):77-98

Salerno RM, Hickok LT (2007) Strengthening bioterrorism prevention: global biological materials management. Biosecur Bioterrorism 5(2):107-116

Sapsford KE, Bradburne C, Delehanty JB, Medintz IL (2008) Sensors for detecting biological agents. Mater Today 11(3):38-49

Shinwari ZK, Khalil AT, Nasim A (2014) Natural or deliberate outbreak in Pakistan: how to prevent or detect and trace its origin: biosecurity, surveillance, forensics. Arch Immunol Ther Exp 62:263-275

Shipman SL, Nivala J, Macklis JF, Chruch GM (2017) CRISPR-Cas encoding of a digital movie into the genomes of a population of living bacteria. Nature 547:345-349. https://doi. org/10.1038/nature23017

Sobel J, Khan AS, Swerdlow DL (2002) Threat of a biological terrorist attack on the US food supply: the CDC perspective. Public Health 359:874-880

Trump BD, Foran C, Rycroft T, Wood MD, Bandolin N, Cains M et al (2018) Development of community of practice to support quantitative risk assessment for synthetic biology products: contaminant bioremediation and invasive carp control as cases. Environ Syst Decisions 38(4):517-527

Trump BD, Cummings CL, Kuzma J, Linkov I (2020a) Synthetic biology 2020: Frontiers in risk analysis and governance. Springer

Trump BD, Galaitsi SE, Appleton E, Bleijs DA, Florin MV, Gollihar JD et al (2020b) Building biosecurity for synthetic biology. Mol Syst Biol 16(7):e9723

Trump BD, Keisler JM, Galaitsi SE, Palma-Oliveira JM, Linkov I (2020c) Safety-by-design as a governance problem. Nano Today 35:100989

Trump BD, Keisler JM, Volk KM, Linkov I (2020d) Biosecurity demands resilience. Environ Sci Technol

Wein LM, Liu Y (2005) Analyzing a bioterror attack on the food supply: the case of botulinum toxin in milk. PNAS 102(28):9984-9989 
Yeh J-Y, Park J-Y, Cho YS, Cho I-S (2012) Animal biowarfare research: historical perspective and potential future attacks. Zoonoses Public Health 59:536-544

Yeh J-Y, Park J-Y, Cho YS, Cho I-S (2013) Countering the livestock-targeted bioterrorism threat and responding with an animal health safeguarding system. Transbound Emerg Dis 60:289-297

Yong E (2018) A controversial virus study reveals a critical flaw in how science is done. The Atlantic. Available at https://www.theatlantic.com/science/archive/2018/10/ horsepox-smallpox-virus-science-ethics-debate/572200/

Zilinskas RA (2017) A brief history of biological weapons programmes and the use of animal pathogens as biological warfare agents. Scientific and Technical Review of the Office International des Epizooties 36(2):415-422

Open Access This chapter is licensed under the terms of the Creative Commons Attribution 4.0 International License (http://creativecommons.org/licenses/by/4.0/), which permits use, sharing, adaptation, distribution and reproduction in any medium or format, as long as you give appropriate credit to the original author(s) and the source, provide a link to the Creative Commons license and indicate if changes were made.

The images or other third party material in this chapter are included in the chapter's Creative Commons license, unless indicated otherwise in a credit line to the material. If material is not included in the chapter's Creative Commons license and your intended use is not permitted by statutory regulation or exceeds the permitted use, you will need to obtain permission directly from the copyright holder. 